\title{
Searching for Molecular Abnormalities in Genetic Diseases by the Use of a Double Labeling Technique. I. Rationale, Techniques, and Initial Evaluation
}

\author{
S. D. J. PENA ${ }^{(40)}$ AND K. WROGEMANN \\ Departments of Pediatrics (Genetics) and Biochemistry, University of Manitoba, Winnipeg, Manitoba, Canada
}

\section{Summary}

To meet the challenge of unravelling the molecular pathology of the ever expanding number of known genetic diseases in man, new efficient investigative techniques have to be designed. A procedure is presented for detection of protein defects in genetic diseases on the basis of structural rather than functional alterations. The technique is based on double labeling of normal and diseased fibroblast proteins followed by extensive fractionation and analysis. The rationale, advantages, and limitations of the procedure are discussed and the technical aspects of its use explained.

\section{Speculation}

Application of double labeling to the systematic analysis of cellular proteins in inherited disorders is a valuable new tool in biochemical genetics.

Biochemical genetics is concerned with the elucidation of the basic genetic defect in inherited diseases. Since determination of the precise nature of the genic defect at the DNA level is generally not yet feasible, efforts are directed towards identification of the molecular abnormality at the level of the protein that represents the gene product. Characterization of this protein defect provides the basis for prenatal diagnosis and carrier detection of the disorder and represents an essential step for a meaningful pathogenetic understanding of the disease process and for rational therapy.

\section{NEED FOR NEW INVESTIGATIVE TECHNIQUES IN BIOCHEMICAL GENETICS}

As of 1975, 2336 single gene disorders were known or suspected in man, but the basic defect was known in only 176 (27). Of those 176 the great majority represents defects in enzymes or otherwise functional proteins. In many of those diseases the clue to the nature of the functional defect was provided by the highly differentiated nature of the afflicted tissue or organ (e.g., in hemolytic anemias) or by the delineation and structural characterization of the compound or compounds whose metabolism is disturbed (e.g., aminoacidopathies, glycogen storage diseases). Nevertheless, a host of single gene disorders remains in which this approach is not possible because a clue to the nature of the basic defect is not apparent. Most of the dysmorphogenetic syndromes and also important diseases such as cystic fibrosis, Duchenne muscular dystrophy, and Huntington's chorea fall into this category. In this context, it is important to emphasize that somatic cells contain a very great number of proteins, perhaps of the order of 20,000 (35), but that we only know a relatively small number of them-only approximately 1300 enzymes were known in 1968(3). For the efficient investigation of the molecular pathology of inherited disorders we need new techniques that do not depend on metabolic clues or on functional properties of the abnormal proteins. In particular, these methods must also be able to detect abnormalities in the very large number of proteins that are still unknown to us.

\section{DOUBLE LABELING TECHNIQUES}

The basic principle of these techniques relies on recent advances in liquid scintillation counting which allow us to discriminate between a mixture of two different radioisotopes contained in a single vial, provided these isotopes differ sufficiently in a nuclear property such as the energy of the particles emitted (21). For instance, if one labels "diseased" fibroblasts in one culture dish with ${ }^{3} \mathrm{H}$-leucine and control fibroblasts in another dish with ${ }^{14} \mathrm{C}$ leucine one can combine the two strains after harvesting and process them identically (see Fig. 1). This processing involves extensive fractionation and it would be almost impossible to treat the two strains identically otherwise. If after extensive fractionation we determine the ratio of counts due to ${ }^{14} \mathrm{C}$-leucine and ${ }^{3} \mathrm{H}$ leucine in each fraction we would expect ideally approximately the same ratio in every fraction. Any abnormal ratio, i.e., a ratio deviating significantly from the expected would suggest a molecular abnormality.

In the recent past double labeling has been applied successfully to the investigation of the molecular pathology of inherited diseases. Mattieu et al. (26) used ${ }^{3} \mathrm{H}:{ }^{1} \mathrm{C}$-fucose dual labeling to demonstrate anomalies in the myelin-associated glycoproteins in "quaking" mice and Phillips et al. (30) used ${ }^{125} \mathrm{I}:{ }^{91}$ I-lactoperoxidase-labeled platelet membranes to demonstrate glycoprotein abnormalities in Glanzmann's thrombasthenia. However, in both of these cases, previous biochemical investigations of these disorders had suggested that the abnormalities resided in the fractions studied. In other cases the application of dual labeling techniques has not been so successful. Both Baig et al. (2) and Changus et al. (8) applied double labeling to the study of the plasma membrane of cultured skin fibroblasts from patients with cystic fibrosis but no consistent abnormalities were detected. The point to be made here is that there is no absolute reason to believe that the basic defect in cystic fibrosis is in the plasma membrane more than in any other subcellular fraction and a search for molecular abnormalities in this situation should include in depth analysis of all subcellular fractions. This approach was partially taken by Fletcher and Lin (12). We believe that, provided that the mutant protein can be differentiated from the wild type either by being present in reduced amounts or by detectable structural alterations, and provided that sufficient fractionation is performed, double labeling should always reveal the molecular defect in a genetic disease. Of course, these are ideal circumstances that are seldom realized in practice. Nevertheless, we propose that application of double labeling to the systematic analysis of cellular proteins in genetic diseases is a valuable new tool that deserves further 


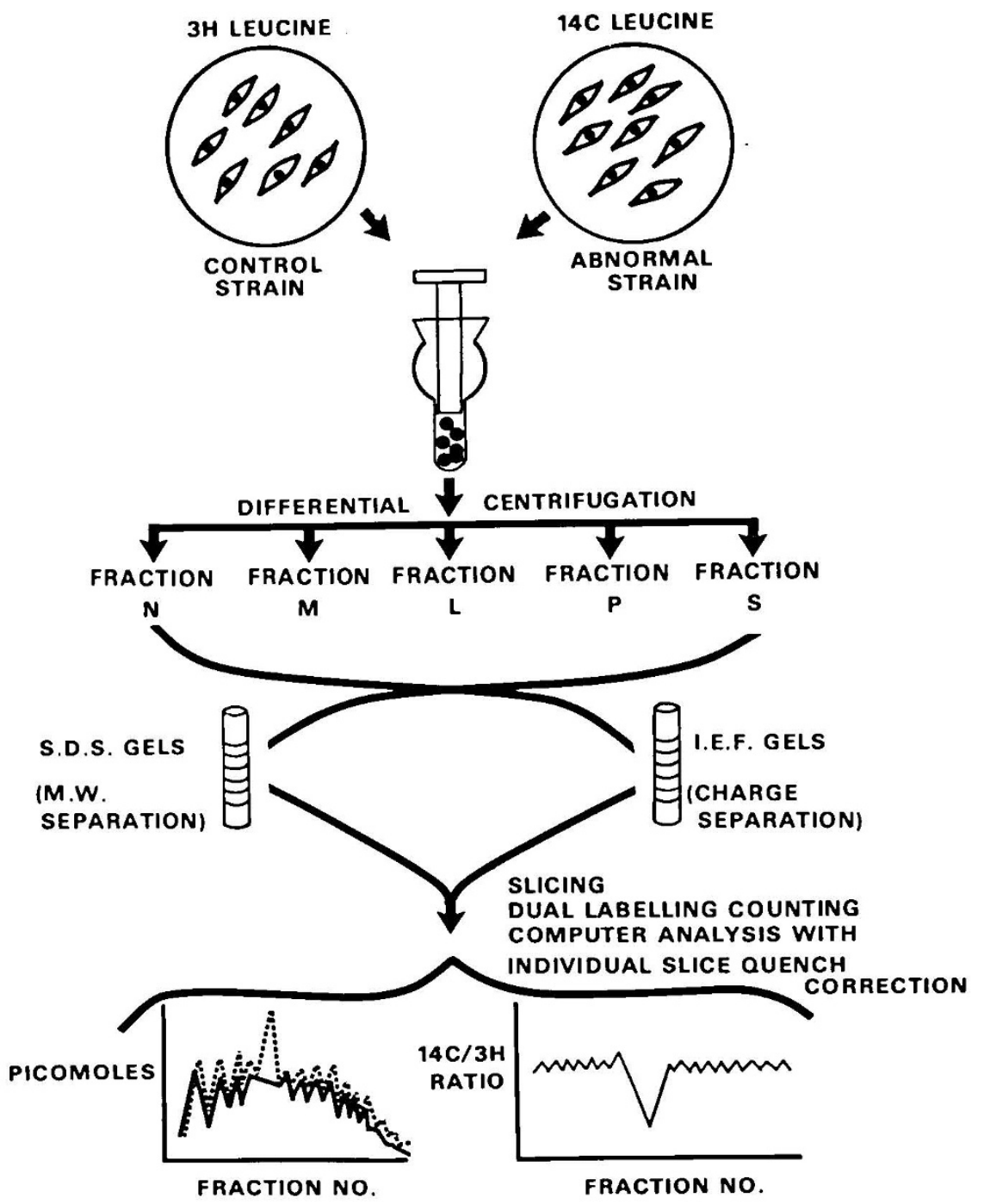

Fig. 1. This scheme depicts the most important steps in the double label technique.

exploration in biochemical genetics. The principles and limitations of the technique will be discussed and the technical aspects explained.

\section{MATERIALS AND METHODS}

\section{CELL CULTURING AND LABELING}

Human skin fibroblast strains GM123, GM186, and GM316 (normal controls) and GM248 (Pompe's disease) were obtained from the Institute for Medical Research, Camden, NJ, and strain DY (Duchenne muscular dystrophy) was obtained from the Repository for Mutant Human Cell Strains, Montreal, Quebec. CHW-1102, a pseudodiploid HPRT-deficient Chinese hamster line (13), and KBF, a diploid human fetal skin fibroblast strain, were kindly provided by Dr. J. L. Hamerton. Cells were grown in McCoy's 5A modified medium (Schwartz) with $10 \%$ fetal calf serum and $5 \%$ human cord serum and subcultivated at a 1:3 split once a week. Cells were used before the 15 th passage. For labeling experiments cells were first grown to confluency in T-150 flasks (Corning). The medium was then removed and monolayers were refed with $30 \mathrm{ml}$ fresh medium containing $40 \%$ fetal calf serum and exposed for $36 \mathrm{hr}$ to either $10 \mu \mathrm{Ci}$ of $U-{ }^{14} \mathrm{C}$-leucine or $50 \mu \mathrm{Ci}$ 4,5- ${ }^{3} \mathrm{H}$-leucine (Amersham-Searle Co.). After $36 \mathrm{hr}$ monolayers were washed three times with $50 \mathrm{ml}$ isotonic sodium phosphate buffer (IPB) and incubated with $5 \mathrm{ml} \mathrm{0.02 \%}$ trypsin (Worthington, twice crystallized) in IPB for $15 \mathrm{~min}$ at $37^{\circ}$. One milliliter of $0.6 \%$ ovomucoid (Worthington) was then added to inhibit the trypsin and cells harvested by Pasteur pipette trituration. Cells were spun at $1000 \mathrm{rpm}$ for $5 \mathrm{~min}$ with an HB-4 rotor in a Sorvall RC2-B centrifuge at $4^{\circ}$ and washed three times with a solution containing $0.25 \mathrm{M}$ sucrose, $1 \mathrm{mM}$ ethylenediamine tetraacetic acid (EDTA), and $5 \mathrm{mM}$ sodium phosphate ( $\mathrm{pH} \mathrm{7.4).}$

\section{CELL FRACTIONATION}

After washes, the cell pellet was suspended in $4 \mathrm{ml} 5 \mathrm{mM}$ sodium phosphate buffer ( $\mathrm{pH}$ 7.4) containing $1 \mathrm{mM}$ EDTA, transferred to a 7-ml Dounce homogenizer, and allowed to sit for $15 \mathrm{~min}$. Homogenization was performed with 4 strokes of a tightly fitting pestle following which $1.3 \mathrm{ml}$ of a $1 \mathrm{M}$ sucrose, $1 \mathrm{mM}$ EDTA, $5 \mathrm{mM}$ sodium phosphate buffer (pH 7.4) were added to restore isotonicity. Subcellular fractionation was done by differential centrifugation, slightly modified from published procedures $(11,34)$. The modified procedure was performed in a Beckman L3-40 ultracentrifuge equipped with a $\omega^{2}$ integrator accessory and using a Beckman 65 rotor. Four particulate fractions (N, M, L, P) and a soluble supernatant (S) were separated by successive centrifugations at increasing speeds and times producing integrated forces corresponding to $S_{\min }$ values of $90,000 \mathrm{~S}(\mathrm{~N}), 17,300 \mathrm{~S}(\mathrm{M})$, $2,300 \mathrm{~S}(\mathrm{~L})$ and $40 \mathrm{~S}(\mathrm{P})$. Occasionally the post- $\mathrm{N}$ fraction supernatant was spun directly at $S_{\min }=2,300 \mathrm{~S}$ and a fraction ML obtained, corresponding to the sum of the $M$ and the $L$ fractions. All pellets were washed once and kept at $-20^{\circ}$ until analyzed. The $\mathrm{S}$ fraction was usually extensively dialyzed against $0.1 \mathrm{M}$ ammonium bicarbonate to remove free radioactive leucine, lyophilized for 3 days to remove the salt, and kept at $-20^{\circ}$ until used. 
POLYACRYLAMIDE GEL ELECTROPHORESIS IN PRESENCE OF SODIUM DODECYL SULFATE (SDS-PAGE)

Aliquots of subcellular fractions were suspended in $500 \mu \mathrm{l} 1 \%$ SDS (Sigma) in $625 \mathrm{mM}$ Tris- $\mathrm{HCl}$ (pH 6.8), and disrupted for 2 min at $100^{\circ}$. Samples were then made $1 \%$ in $\beta$-mercaptoethanol and heated again at $100^{\circ}$ for $1 \mathrm{~min}$ followed by the addition of 1 drop of glycerol and $10 \mu \mathrm{l}$ of a $0.01 \%$ aqueous solution of bromophenol blue. SDS electrophoresis (SDS-PAGE) was performed using the discontinuous buffer system of Maizel (25). Stacking gels contained $0.1 \%$ SDS, $3.0 \%(\mathrm{w} / \mathrm{v})$ acrylamide (BIORAD), $38 \%$. (w/v) $N, N^{\prime}$-methylene-bis-acrylamide (Bis, BIORAD), and were polymerized by the addition of $0.125 \%(\mathrm{v} / \mathrm{v}) N, N, N^{\prime}, N^{\prime}-$ tetramethylenediamine (TEMED, Eastman) and $0.10 \%(\mathrm{w} / \mathrm{v})$ ammonium persulfate. Separating gels contained $6 \mathrm{M}$ urea, $13 \%$ or $10 \%$ acrylamide, and $0.26 \%$ or $0.20 \%$ Bis, respectively, and were polymerized by the addition of $0.06 \%$ TEMED and $0.04 \%$ ammonium persulfate. Separating gels were cast to a height of $20 \mathrm{~cm}$ in $0.6 \times 25-\mathrm{cm}$ tubes and stacking gels measured $2 \mathrm{~cm}$. Electrode buffer contained $50 \mathrm{mM}$ Tris, $0.38 \mathrm{M}$ glycine, and $0.1 \%$ SDS, pH 8.3. A constant voltage of $60 \mathrm{~V}$ was applied until the sample had entered the stacking gel followed by $120 \mathrm{~V}$ for approximately 20 hr. Bovine serum albumin, ovalbumin, alcohol dehydrogenase, $\alpha$-chymotrypsinogen, myoglobin, lysozyme, and ribonuclease (all obtained from Sigma) were used as molecular weight markers.

\section{GEL ISOELECTRIC FOCUSING (IEF)}

Gels containing $1 \%$ ampholines (LKB), pH 3.5-10, 5.0\% acrylamide, and $0.17 \% \mathrm{Bis}$ were cast in $0.6 \times 16-\mathrm{cm}$ tubes. The samples were polymerized into the gel. Focusing was carried out in an apparatus of our own design which allows use of small $(50-\mathrm{ml})$ electrolyte volumes and provides cooling in direct contact with the gel tubes. The upper (anode) compartment contained 5\% (v/v) orthophosphoric acid and the lower one $5 \%(\mathrm{v} / \mathrm{v})$ ethylenediamine. The temperature was maintained at $4^{\circ}$ and the power, provided by an Ortec 4100 pulsed constant power supply, was regulated as follows: $50 \mathrm{~V}$ for $0.5 \mathrm{hr}, 100 \mathrm{~V}$ for $1 \mathrm{hr}$, and $150 \mathrm{~V}$ for $16 \mathrm{hr}$, all at a pulse rate of $50 \mathrm{pps}$ and at 0.5 microfarads. At the end of the run the power was raised to $300 \mathrm{~V}$ and $100 \mathrm{pps}$ for 2 $\mathrm{min}$ and $400 \mathrm{~V}$ and $200 \mathrm{pps}$ for $2 \mathrm{~min}$. This scheme was modified from that of Klose (23). The $\mathrm{pH}$ gradient was determined by cutting the gel into $2-\mathrm{mm}$ minced fractions with a Gilson Aliquogel fractionator and measuring the $\mathrm{pH}$ at $5^{\circ}$ in $0.5-\mathrm{ml}$ water extracts with a Radiometer PHM62 standard $\mathrm{pH}$ meter equipped with a Radiometer $\mathrm{pH}$ microelectrode.

\section{ASSAY OF RADIOACTIVITY IN GELS}

Gels were sliced in 2-mm fractions, minced, and extruded directly into scintillation vials by a Gilson Aliquogel fractionator. After drying overnight in an oven at $50^{\circ}$ the vials were prepared for counting by sequential addition of $100 \mu \mathrm{l} \mathrm{H} \mathrm{H}_{2} \mathrm{O}, 600 \mu \mathrm{l}$ NCS tissue solubilizer (Amersham-Searle Co.) and $12 \mathrm{ml}$ of a scintillation cocktail containing $0.4 \%$ Omnifluor (New England Nuclear) in toluene. After capping vials were vigorously mixed and stored overnight in the dark before counting. Samples were counted to $5 \%$ accuracy in Beckmann scintillation systems, model LS350, LS250, or LS150, all equipped and operated with automatic quench compensation, and contained at least $12,000 \mathrm{cpm}$ of each radioisotope. Counting efficiencies with narrow ${ }^{3} \mathrm{H}$ and ${ }^{14} \mathrm{C}$ windows were approximately $38 \%$ and $71 \%$, respectively. Quench curves were prepared as described by Boeckx et al. (5). Vials with less than twice background counts were ignored in the analysis.

\section{ANALYSIS AND PLOTTING OF DATA}

Liquid scintillation data were punched on paper tape and analyzed by a computer program, SCINT II (36) operative in a CDC (Control Data Corporation) 1700 computer system. This program, an expanded version of SCINT (5), performs individual quench correction and compensation for spillover of ${ }^{14} \mathrm{C}$ counts into the ${ }^{3} \mathrm{H}$ channel. The program computes disintegrations per min and picomoles of isotope incorporated into each fraction and the ratio of ${ }^{14} \mathrm{C}:{ }^{3} \mathrm{H}$ incorporation, normalizes these data, and plots them against gel fractions. The program also calculates and prints several useful statistics such as the variance and standard deviation of the normalized ${ }^{14} \mathrm{C}:{ }^{3} \mathrm{H}$ ratio.

\section{RESULTS AND DISCUSSION}

\section{VARIABILITY IN TECHNIQUE}

In order to determine the resolution of the technique as well as to have an idea of the factors determining variability in the system, control experiments involving comparison of identical or radically different protein populations were performed. In the first experiment, shown in Figure 2, the same culture flask was labeled with both ${ }^{14} \mathrm{C}$ - and ${ }^{3} \mathrm{H}$-leucine. The profiles should be identical and differences between them represent the lower limit of resolution by the system. It can be seen from the small fluctuation of the normalized ${ }^{14} \mathrm{C}:{ }^{3} \mathrm{H}$ ratio that differences were indeed very small. In marked contrast is the plot shown in Figure 3, which displays a comparison of the supernatant proteins of a human fibroblast strain (KBF) and a Chinese hamster fibroblast line (CHW-1102). Here the distributions are markedly different and the ${ }^{14} \mathrm{C}:{ }^{3} \mathrm{H}$ ratios show wide fluctuations. A useful summarizing index of the differences between protein distributions seems to be the VNR, i.e., the variance of the normalized ${ }^{14} \mathrm{C}:{ }^{3} \mathrm{H}$ ratio; its numeric value is 0.0018 for Figure 2 and 0.0727 for Figure 3. To ascertain whether the VNR is truly a useful index, two experiments, each comparing ${ }^{14} \mathrm{C}$ - and ${ }^{3} \mathrm{H}$-labeled supernatant proteins from replicate cultures of the same strain (not shown) and supernatant proteins from different human fibroblast strains obtained from normal individuals, were performed (Fig. 4). The VNRs for all these distributions are shown in Table 1. Examination of these numbers reveals a correlation between the expected degree of difference of the profiles and the VNR. Accordingly, the VNR of the comparison shown in Figure 2 represents random error in the distribution and counting of the two isotopes, i.e., the variance inherent in the technical procedures. The VNRs of the comparisons of replicate dishes of the same fibroblast strains are on average slightly larger than the one of Figure 2, indicating the very small added variability of culture conditions. Even larger is the VNR of the comparison of different normal fibroblast strains (Fig. 4), probably reflecting differences in the genotype of the strains, i.e., biochemical individuality, but also epigenetic phenomena. Finally the

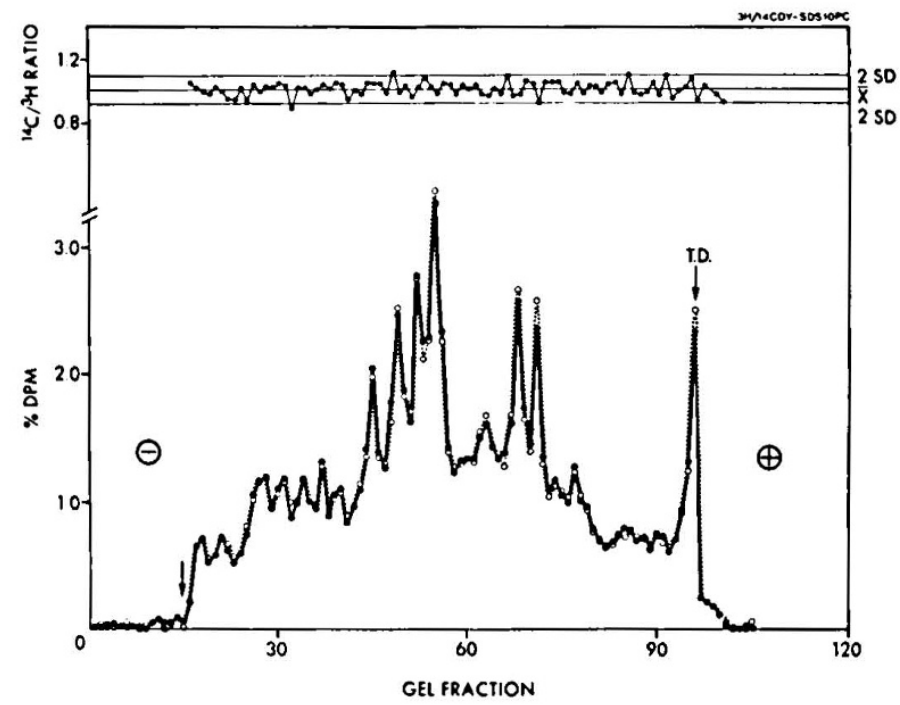

Fig. 2. A dish of human diploid skin fibroblast strain DY was labeled with both ${ }^{3} \mathrm{H}$ - and ${ }^{14} \mathrm{C}$-leucine. After subcellular fractionation supernatant proteins were run on $10 \%$ SDS-PAGE. The plot shows the distribution of ${ }^{14} \mathrm{C}$ - and ${ }^{3} \mathrm{H}$-leucine counts in the gel. An arrow indicates the beginning of the separating gel. T.D. indicates the tracking dye band. 


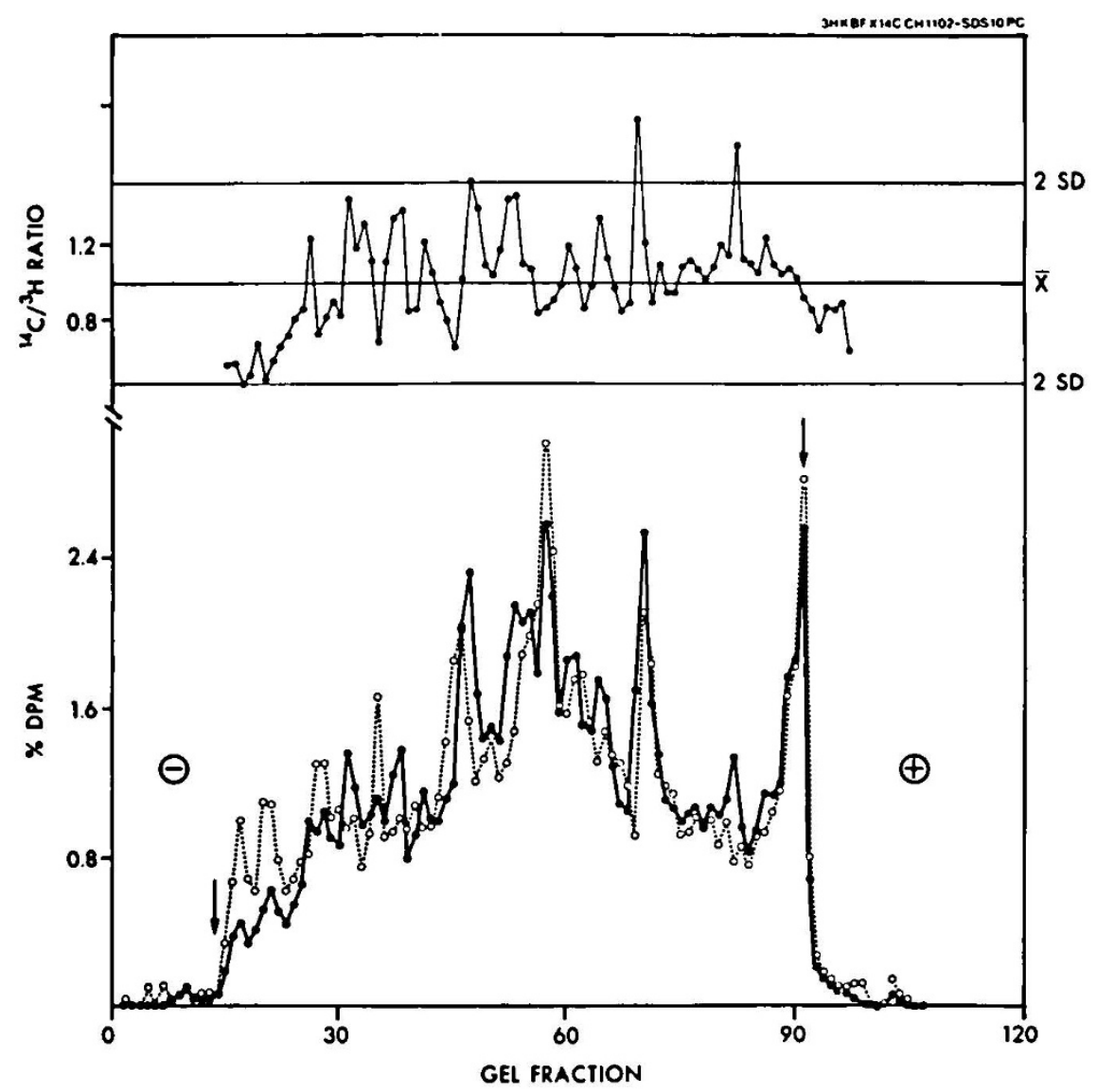

Fig. 3. Fetal human fibroblasts (KBF) and HGPT-deficient Chinese hamster fibroblasts (CHW-1102) were labeled with ${ }^{3} \mathrm{H}$-leucine $(\mathrm{O} \cdots \mathrm{O})$ and ${ }^{14} \mathrm{C}$-leucine (-), respectively, and subcellular fractionation done as described in Materials and Methods. The plots show the distribution of the supernatant proteins of the double labeled mixture after separation by $10 \%$ SDS-PAGE. Arrows indicate the beginning of the separating gel and the tracking dye band.

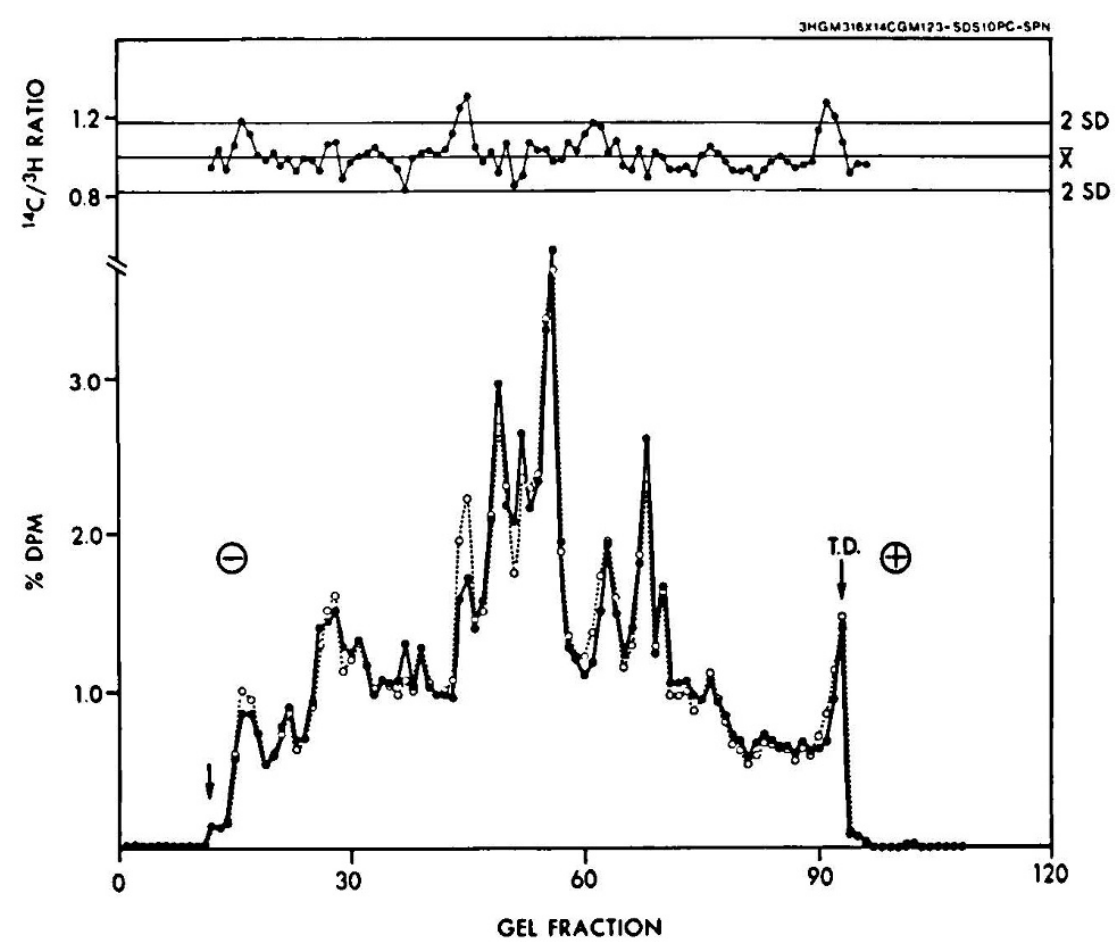

Fig. 4. Two human fibroblast strains derived from normal individuals (GM316 and GM123) were labeled with ${ }^{3} \mathrm{H}$-leucine $(\mathrm{O} \cdots \mathrm{O})$ and ${ }^{14} \mathrm{C}$-leucine (--O), respectively. The supernatant fraction obtained by subcellular fractionation was run on 10\% SDS-PAGE and double labeling counting performed after slicing of the gel in 2-mm fractions. Arrow indicates beginning of separating gel. Tracking dye band (T.D.) is also marked with an arrow. 
human-hamster comparison reflects differences between different species. In this context it would be interesting to examine whether the VNR of comparisons between species correlates with evolutionary divergence and whether it could then be used as a measure of genetic distance.

\section{DEFINITION OF ABNORMAL RATIO}

In single gene disorders we expect biochemical abnormalities to be confined to very few proteins, most often just one. This abnormality will hopefully be expressed as a "significant" deviation of the ${ }^{14} \mathrm{C}:{ }^{3} \mathrm{H}$ ratio from average in one or a few vials. We arbitrarily consider "significant" a deviation larger than 2 SD. To facilitate visual ascertainment of deviant ratios, lines indicate the 2 SD value in the ratios plot.

In order to have an idea of how often marked ratio abnormalities can be found in the absence of disease as well as to have an idea of factors contributing to their appearance, two leucine double labeling experiments comparing "normal" strains were performed. Figures 4 and 5 are good examples of the several plots obtained. Although the variability is low, some deviant ratios are immediately apparent on observation of these plots.

In Figure 5 an area of excess ${ }^{14} \mathrm{C}$-leucine counts can be identified just ahead of the tracking dye (T.D.) area. This "defect" was seen

Table 1. Variance of normalized ratio (VNR) for several double labeled supernatant protein patterns

\begin{tabular}{lcc}
\hline & Characteristics of comparison & VNR \\
\hline${ }^{3} \mathrm{H}:{ }^{14} \mathrm{C}$ DY & Both labels in same dish & 0.0018
\end{tabular}

${ }^{3} \mathrm{H}$ GM $248 \times{ }^{14} \mathrm{C}$ GM 248

${ }^{3} \mathrm{H} \mathrm{KBF} \times{ }^{14} \mathrm{C} \mathrm{KBF}$

Same strain, different dishes

0.0011

0.0026

${ }^{3} \mathrm{H} \mathrm{GM} 316 \times{ }^{14} \mathrm{C}$ GM 186

${ }^{3} \mathrm{H}$ GM $316 \times{ }^{14} \mathrm{C}$ GM 123$\}$

Different normal human

0.0214

strains

0.0079

${ }^{3} \mathrm{H} \mathrm{KBF} \times{ }^{14} \mathrm{C}$ CHW $1102 \quad$ Different species 0.0727 in all leucine double labeling plots of particulate subcellular fractions obtained by us. Other groups have also observed this phenomenon (32), which is generally considered to be due to lipid components migrating to that area of the gel, perhaps together with SDS micelles. The relative excess of ${ }^{14} \mathrm{C}$ radioactivity observed is caused by differential metabolism of radioactive carbon and hydrogen atoms $\left({ }^{14} \mathrm{C}\right.$-leucine is uniformly labeled whereas ${ }^{3} \mathrm{H}$-leucine is labeled only in positions 4 and 5) in the conversion of leucine to acetyl-CoA and acetoacetate, which are lipid precursors (24). Since these "lipid abnormalities" inflate the VNRs, the lines indicating $2 \mathrm{SD}$ values in the plot of normalized ratios become rather useless. In order to preserve this most useful visual guideline, we have consistently obtained new ratio plots after removing the computer cards with the anomalous "lipid" ratios. In consequence, the figures presented in this and the following articles will show the "lipid defects" (whenever present) only in the "\% DPM" plot. Corresponding deviations will not be seen in the plots of the normalized ${ }^{14} \mathrm{C}:{ }^{3} \mathrm{H}$ ratios.

The fairly common observation of deviant ratios in comparisons of strains derived from apparently normal individuals is disturbing. Obviously these deviant ratios did not originate from "true molecular defects" but rather represent, as mentioned above, genotypic and epigenetic differences between normal strains. If double labeling is to be useful for the study of diseases, it is evident that we need to define criteria by which to distinguish true "abnormal" ratios from those deviations arising from nonpathologic differences between strains. We should be aware that as soon as these criteria are established and followed, errors of classification will be made, since the criteria will not be perfect. In analogy to statistical significance testing we can classify these errors in two main categories (see Table 2).

Type I Error. This type of error occurs if we consider a ratio abnormal when in fact it is caused by nonpathologic differences. Possible causes for this kind of error are many and only a few are listed in Table 2. Nevertheless, we can minimize the probability of incurring such errors by carefully controlling the tissue culture. conditions and by incorporating into our criteria for abnormality or ratios the necessity for highest reproducibility. Accordingly, to be considered abnormal a deviant ratio should repeat itself with

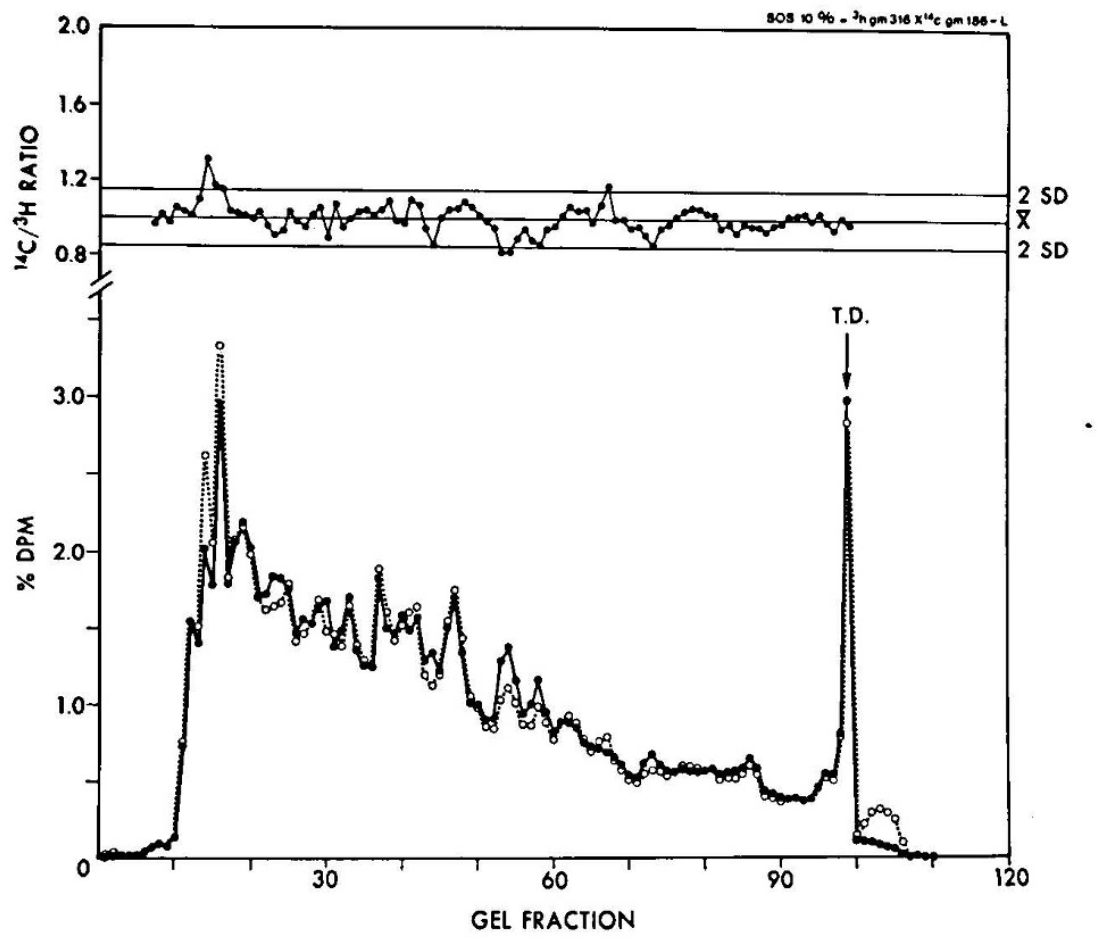

Fig. 5. SDS-PAGE (10\%) of fraction $\mathrm{L}$ of a leucine-double labeled mixture of two different fibroblast strains obtained from normal individuals. Strain GM316 was labeled with ${ }^{3} \mathrm{H}$-leucine (_- ) and strain GM186 was labeled with ${ }^{14} \mathrm{C}$-leucine $(\mathrm{O} \cdots \mathrm{O})$. The tracking dye band (T.D.) is marked with an arrow. 
Table 2. Pitfalls in double labeling

\begin{tabular}{cl}
\hline Type I error (finding a defect when in fact there is none) \\
Causes: & $\begin{array}{l}\text { Biochemical individuality } \\
\text { Differences in biological state of the cultures e.g., log vs. } \\
\text { confluency, senescence, etc. } \\
\text { Mycoplasma contamination }\end{array}$ \\
& $\begin{array}{l}\text { Differential behavior of labels } \\
\text { Rigorous control of culture conditions } \\
\text { Relution: } \\
\text { Repeated with different "diseased" and control strains } \\
\text { Reverse labels }\end{array}$ \\
Type II error (missing a defect when in fact it is present) \\
Causes: $\quad \begin{array}{l}\text { Weak signal to noise ratio } \\
\text { "Cover-up" effect }\end{array}$ \\
Solution: $\quad \begin{array}{l}\text { Increase analytic resolution } \\
\text { Change labels }\end{array}$ \\
\hline
\end{tabular}

different strains of "diseased" and control fibroblasts and also should be independent of which strain receives the ${ }^{3} \mathrm{H}$ or ${ }^{14} \mathrm{C}$ label. We are aware that occasionally genetic heterogeneity $(4,7)$ may be responsible for the nonreproducibility of deviant ratios and this possibility should be taken into consideration when one of several mutant strains behaves anomalously.

Type II Error. This type of error consists in missing a molecular abnormality when it is in fact present. We believe this type of error to be more serious and more difficult to avoid than the type I error. It has two main causes which will be discussed below.

Weak signal to noise ratio: Sometimes the protein which is abnormal may be present in very small amounts or incorporates leucine poorly. A solution to this problem, whenever possible, is to use other labels. For instance, we know that glycoproteins constitute only a fraction of all leucine-labeled proteins but they can be examined selectively by glucosamine or fucose labeling. Also, we have to consider the possibility that the mutant protein, although abnormal in structure, may be present in normal amounts and not differ from the wild type in molecular weight or charge and hence not be detected by SDS-PAGE or IEF, respectively. In this case the molecular defect would not be detected by the double labeling procedure. However, we believe that the probability of this occurrence is small. Evidence has been mounting in recent years in favor of the concept that structurally abnormal proteins may be selectively degraded at a faster rate than normal ones in both bacterial and mammalian systems (14, 15, 31). Accordingly, Capechi et al. (6) found decreased levels of enzyme protein in all of four cross-reactive material positive missense mutants of hypoxanthine-guanine-phosphoribosyltransferase in mouse $L$ cells. It is then evident that the presence of mutant proteins in normal amounts should be an uncommon phenomenon in genetic diseases.

"Cover-up" effect: The extent of analytical fractionation now possible is limited if compared to the total number of proteins present in the cell. The ideal situation of having one protein only per fraction is generally not feasible. Abnormal ratios generated by decreased or absent label incorporation in a mutant protein may be masked by the presence of other normal proteins in that fraction, producing the "cover-up" effect. For instance, the large majority of proteins have their isoelectric point (pI) in the range 4-7 (33). Consequently, isoelectric focusing gels of fibroblast supernatant proteins in the $3.5-10 \mathrm{pH}$ range show crowding and poor resolution of bands in the central portion of the gel. When we compared the distribution of Chinese hamster and human fibroblast supernatant proteins by IEF in the 3.5-10 range the VNR was only 0.0081 compared to 0.0727 for SDS-PAGE (Fig. 3 ). This is another aspect of the "cover-up" effect and points to one of the limitations of IEF in this type of analysis. Of course, to obtain more uniform distribution of proteins in the gel one may use ampholines with more restricted $\mathrm{pH}$ ranges but then the danger exists of excluding the abnormal protein from the gel.

Several methods may be employed to decrease the "cover-up" effect and increase analytic resolution. When necessary, we have cut out selected areas of IEF gels and, after appropriate disruption with SDS and reduction, ran a "second dimension" by SDSPAGE in glass tubes. We are currently investigating the possibility of using the recently developed double label autoradiography method (16) in conjunction with the newer high resolution twodimensional electrophoresis of proteins $(1,28)$.

\section{CRITERIA FOR ABNORMALITY OF RATIOS}

With the above considerations in mind we can now define criteria for considering a given ratio abnormal. As mentioned previously these criteria are arbitrary and occasionally one of them may have to be waived. They are: 1) the ratio should deviate more than 2 SD from the mean; 2) a deviant ratio should correspond to a protein peak in the profile; 3 ) the deviant ratio should be reproducible with different disease and control fibroblast strains; 4) the reversal of the labels should result in a ratio deviation in the opposite direction.

To examine better these criteria as well as to test clinically the power of double labeling in detecting molecular defects in genetic diseases we applied our technique to a model disease, Pompe's disease (glycogenosis II) a lysosomal disease associated with deficiency of acid $\alpha-1,4$-glucosidase (acid maltase) activity $(18,19)$. Results of these experiments will be presented in the next article in this series (29).

\section{CONCLUSION}

We propose that application of double labeling in conjunction with extensive protein fractionation to the systematic analysis of genetic diseases is a valuable new tool in biochemical genetics. The principles and limitations of the technique were discussed and the technical aspects of its use explained. The technique does not depend on metabolic clues or on functional properties of the defective protein, and hence can be applied to genetic disorders of obscure physiopathology. Using the abnormal ratio as a marker, biochemical characterization of the protein involved is possible in terms of structural properties such as molecular weight and isoelectric point permitting in a few cases identification of the protein by reference to standard tables $(10,20,33)$.

We hope that application of this technique to important diseases of obscure pathophysiology such as cystic fibrosis, Duchenne muscular dystrophy, and Huntington's chorea will lead to characterization of molecular defects in tissue culture cells and that in turn these findings will lead to better pathogenetic understanding of these disorders and hopefully prenatal diagnosis of these conditions.

\section{REFERENCES AND NOTES}

1. Ames, G. F. -L., and Nikaido, K.: Two-dimensional gel electrophoresis of membrane proteins. Biochemistry, 15: 616 (1976).

2. Baig, M. M., Cetorelli, J. J., and Roberts, R. M.: Plasma membrane components of skin fibroblasts from normal individuals and patients with cystic fibrosis. J. Pediat., 86: 72 (1975).

3. Barmann, T. E.: Enzyme Handbook, p. 2 (Springer, New York, 1969).

4. Bearn, A. G.: Cell culture in inherited disease-with some notes on genetic heterogeneity. N. Engl. J. Med., 286: 764 (1972).

5. Boeckx, R. L., Protti, D. J., and Dakshinamurti, K.: "SCINT", a Fortran IV program for the analysis of data from doubly labeled and variably quenched liquid scintillation samples. Anal. Biochem., 53: 491 (1973).

6. Capechi, M. R., Capechi, N. E., Hughes, S. H., and Wahl, G. M.: Selective degradation of abnormal proteins in mammalian tissue culture cells. Proc. Nat. Acad. Sci., U. S. A., 71: 4732 (1974).

7. Childs, B., and Der Kaloustian, V. M.: Genetic heterogeneity. N. Engl. J. Med., 279: 1205 (1968).

8. Changus, J. E., Quissell, D. O., Soukup, M. R., and Pitot, H. C.: Studies on the synthesis of plasma membrane proteins from patients with cystic fibrosis. Amer. J. Pathol., 80: 317 (1975).

9. Cox, R. P., and King, J. C.: Gene expression in cultured mammalian cells. Int. Rev. Cytol., 43: 282 (1975).

10. Darnall, D. W., and Klotz, I. M.: Subunit constitution of proteins: A table. Arch. Biochem. Biophys., 166: 651 (1975).

11. Duve, C., Pressman, B. C., Gianetto, R., Wattiaux, R., and Appelmans, F.: Tissue fractionation studies. 6 . Intracellular distribution patterns of enzymes in rat liver tissues. Biochem. J., 60: 604 (1955).

12. Fletcher, D. S., and Lin, T. -Y.: Incorporation of L-leucine and D-glucosamine into skin fibroblasts derived from cystic fibrosis and normal individuals. Clin. 
Chim. Acta, 44: 5 (1973).

13. Gee, P. A., Ray, M., Mohandas, T., Douglas, G. R., Palser, H. R., Richardson, B., and Hamerton, J. L.: Characteristics of an HPRT-deficient Chinese hamster cell line. Cytogenet. Cell Genet., 13: 437 (1974).

14. Goldberg, A. L., and Dice, J. F.: Intracellular protein degradation in mammalian and bacterial cells. Annu. Rev. Biochem., 43: 835 (1974).

15. Goldberg, A. L., and St. John, A. C.: Intracellular protein degradation in mammalian and bacterial cells. Part 2. Annu. Rev. Biochem., 45: 747 (1976).

16. Gruenstein, E. I., and Pollard, A. L.: Double-label autoradiography on polyacrylamide gels with ${ }^{3} \mathrm{H}$ and ${ }^{14} \mathrm{C}$. Anal. Biochem., 76: 452 (1976).

17. Harris, H., and Hopkinson, D. A.: Average heterozygosity per locus in man: An estimate based on the incidence of enzyme polymorphisms. Ann. Hum. Genet., 36: 9 (1972).

18. Hers, H. G.: $\alpha$-Glucosidase deficiency in generalized glycogen-storage disease (Pompe's disease). Biochem. J., 86: 11 (1963).

19. Hers, H. G., and de Barsy, T.: Type II glycogenosis (acid maltase deficiency). In: H. G. Hers and F. van Hoof: Lysosomes and Storage Diseases, pp. 197-216 (Academic Press, New York, 1973).

20. Hopkinson, D. A., Edwards, Y. H., and Harris, H.: The distribution of subunit number and subunit sizes of enzymes: A study of the products of 100 human gene loci. Ann. Hum. Genet., 39: 383 (1976)

21. Horrocks, D. L.: Applications of Liquid Scintillation Counting, pp. 227-237 (Academic Press, New York, 1974).

22. Kaufman, M., and Pinsky, L.: Skin biopsy site and biology of fibroblast strains. Lancet, $i: 1202$ (1973).

23. Klose, J.: Protein mapping by combined isoelectric focusing and electrophoresis of mouse tissues-A novel approach to testing for induced point mutations in mammals. Humangenetik, 26: 231 (1975).

24. Lehninger, A. L.: Biochemistry, Ed. 2 (Worth Publishers, New York, 1975).

25. Maizel, J. V. Jr.: Polyacrylamide gel electrophoresis of viral proteins. Methods Virol., S: 179 (1972).

26. Mattieu, J. M., Brady, R. O., and Quarles, R. H.: Anomalies of myelin-associated glycoproteins in "quaking" mice. J. Neurochem., 22: 291 (1974).

27. McKusick, V.: Mendelian Inheritance in Man-Catalogs of Autosomal Dominant, Autosomal Recessive and X-linked Phenotypes, Ed. 5 (Johns Hopkins University Press, Baltimore, 1975).
28. O'Farrell, P. H.: High resolution two-dimensional electrophoresis of proteins. J. Biol. Chem., 250: 4007 (1975).

29. Pena, S. D. J., Quilliam, N. M., Hamerton, J. L., and Wrogemann, K.: Searching for molecular abnormalities in genetic diseases by the use of a double labeling technique. II. Deficiency of a basic protein in fibroblasts of patients with Pompe's disease. Pediat. Res., 12: 894 (1978).

30. Phillips, P. R., Jenkins, C. S. P., Luscher, E. F., and Larrieu, M. -J.: Molecular differences of exposed surface proteins on thrombasthenic platelet plasma membrane. Nature, 257: 599 (1975).

31. Prouty, W. F.: Degradation of abnormal proteins in HeLa cells. J. Cell Comp. Physiol., 88: 371 (1976).

32. Ramirez, G., Levitan, I. B., and Mushynski, W. E.: Double isotope studies on brain protein synthesis with $\left({ }^{3} \mathrm{H}\right)$ - and $\left({ }^{14} \mathrm{C}\right)$-leucine: A warning. Brain Res., 43: 309 (1972).

33. Righetti, P. G., and Caravaggio, T.: Isoelectric points and molecular weights of proteins-A table. J. Chromatogr., 127: 1 (1976).

34. Tulkens, P., Beaufay, H., and Trouet, A.: Analytical fractionation of homogenates from cultured rat embryo fibroblasts. J. Cell Biol., 63: 383 (1974).

35. Wallach, D. F. H.: Possible processes in the immune surveillance of the intracellular space. J. Theor. Biol., 39: 321 (1973).

36. Wrogemann, K., Pena, S. D. J., Blanchaer, M. C., Reimer, G. D., and Corby, P.: SCINT II, an improved program for the statistical analysis and plotting of variably quenched dual-labeled liquid scintillation samples. Anal. Biochem., 81: 472 (1977).

37. We are grateful to Ms. A. Vust for expert technical help. We thank Dr. J. L. Hamerton, Dr. F. C. Stevens, and Dr. M. C. Blanchaer for critical advice. We thank the Computer Department for the Health Sciences and the Health Sciences Instructional Media Centre for valuable cooperation.

38. Dr. S. D. J. Pena is a postdoctoral fellow of The Medical Research Council of Canada.

39. This research was supported by the Muscular Dystrophy Association of Canada and The Manitoba Heart Foundation.

40. Requests for reprints should be addressed to: Dr. S. D. J. Pena, Montreal Neurological Institute, Montreal, Quebec H3A 2B4 (Canada).

41. Received for publication June 1, 1977

42. Accepted for publication November 16, 1977. 